\title{
Assessment of myocardial perfusion with Tc-99m: image is everything
}

\author{
Seth T. Dahlberg
}

\section{See related article, pp. 571-579}

Despite the multiple imaging modalities that are now available for the diagnosis and assessment of coronary artery disease, radionuclide myocardial perfusion imaging continues to enjoy widespread use due to its combination of diagnostic accuracy and well-established prognostic utility.

After initial research demonstrated the feasibility of perfusion imaging with the metallic cation $\mathrm{K}-42,{ }^{1}$ Tl-201, another metallic cation, was proposed as a potassium analog for medical use. ${ }^{2}$ Extensive research with cell culture, isolated heart and intact animal models showed that thallous ion has a relatively high myocardial extraction, in part via $\mathrm{Na}-\mathrm{K}$ ATPase, that permits noninvasive assessment of relative regional myocardial blood flow. ${ }^{3}$ Experimental models clarified the effect of variable coronary blood flow and myocardial injury on thallium uptake and clearance., ${ }^{4,5}$ Moderate tracer washout resulting in "redistribution", permitted the differentiation of ischemic from infarcted myocardium with a practical single day imaging protocol, ${ }^{6}$ and Tl-201 was approved by the U.S. Food and Drug Administration (FDA) for clinical use in 1977. However, despite widespread clinical use, the relatively long half-life and suboptimal photon energy of Tl-201 for Anger camera imaging led to the search for perfusion agents labeled with Tc-99m.

During the 1980s numerous cationic complexes of Tc-99m were evaluated for use as potential myocardial perfusion agents. The standard assessment involved screening compounds in rodents, evaluation of promising compounds in large animals, with subsequent study

From the Divisions of Nuclear Medicine and Cardiology, University of Massachusetts Memorial Medical Center, Worcester, MA.

Reprint requests: Seth T. Dahlberg, Division of Nuclear Medicine, University of Massachusetts Memorial Medical Center, Worcester, MA; seth.dahlberg@umassmed.edu.

J Nucl Cardiol 2009;16:493-6.

$1071-3581 / \$ 34.00$

Copyright (C) 2009 by the American Society of Nuclear Cardiology. doi:10.1007/s12350-009-9082-0 in humans of the most promising compounds. Tertbutylisonitrile (TBIN), carboxyisopropyl isonitrile (CPI), trimethylphosphite (TMP), dimethoxyphosphinoethane (POM-POM) and several analogues of dimethylphosphinoethane (DMPE) were synthesized and appeared promising in various experimental animal models. ${ }^{7-9}$ However, subsequent evaluation in humans showed these compounds to have poor myocardial retention, delayed blood pool clearance due to binding with blood components, high background lung uptake or high adjacent organ (liver/spleen) uptake. ${ }^{10-12}$ Gerundini et $\mathrm{al}^{13}$ concluded that animal studies were not adequate to evaluate potential Tc-99m-labeled myocardial perfusion compounds. Deutsch et $\mathrm{al}^{14}$ described 'The Noah's Ark Experiment', an attempt to predict the behavior of Tc-99m complexes using: (1) planar cardiac imaging in multiple animal species to screen new compounds, (2) early imaging studies of promising compounds in human volunteers, (3) biodistribution studies in rodents to refine structure-distribution relationships among structural analogues, and (4) final evaluation of the best candidate compound in human volunteers and patients. With this model of tracer evaluation, imaging assumed an earlier, more prominent role in the development cycle.

In the late 1980s two Tc-99m labelled perfusion agents were studied as myocardial perfusion agents in several experimental models and in human subjects. Teboroxime (TB) is a neutral, lipophlic boronic acid adduct of Tc-99m, and sestamibi (MIBI) is a lipophilic cationic isonitrile complex of Tc-99m.

TB shows the highest myocardial extraction and most accurate estimation of regional myocardial blood flow among the Tc-99m labelled tracers and Tl-201. Myocardial retention of the neutral compound is relatively less affected by myocyte injury, potentially permitting assessment of blood flow despite myocardial infarction. $^{15,16}$ While TB shows moderate clearance from isolated cardiac myocytes, the tracer shows rapid clearance in isolated hearts, canine models and patients, in part due to tracer binding to blood components. ${ }^{17-20}$ The tracer also shows prominent hepatic uptake. ${ }^{21}$

MIBI shows avid uptake and moderate clearance in isolated myocytes, localizing in cellular mitochondria. ${ }^{22}$ However, despite this avid myocardial cellular uptake, the tracer shows only moderate extraction in isolated hearts and canine models due to impaired diffusion of 
the large complex across the capillary endothelial barrier. ${ }^{23,24}$ This moderate extraction results in a significant underestimation of hyperemic flow, beyond roughly $2 \mathrm{~mL} / \mathrm{minute} / \mathrm{g}$, during pharmacologic stress. In patients, a modest coronary flow reserve of 2:1 or higher correlates with the absence of a perfusion defect with MIBI imaging. ${ }^{25}$ Like TB, MIBI also shows prominent hepatic uptake.

Both compounds appeared promising, permitted accurate diagnosis of coronary artery disease compared with coronary angiography and were approved by the FDA 2 days apart in December 1990. With the FDA approval of IV dipyridamole that same month, one might have expected the more accurate measurement of hyperemic flow by TB to be an advantage. However, the combination of rapid myocardial clearance and prominent sustained liver uptake required very rapid imaging that was logistically challenging. ${ }^{26}$ While some laboratories did evaluate rapid SPECT protocols for $\mathrm{TB},{ }^{27,28}$ the tracer's rapid myocardial clearance and prominent hepatic uptake made it appear best suited for rapid planar imaging. Such rapid imaging might permit faster patient throughput, but the longer imaging with MIBI gave higher image quality, well suited to gated SPECT imaging. With the transition to SPECT imaging MIBI achieved wide acceptance. However, the major drawback in image quality for MIBI continued to be prominent, early hepatic uptake that sometimes interfered with assessment of the inferior cardiac wall. Various strategies such as ingestion of a fatty meal, milk, chilled or carbonated water have been suggested to deal with this.

In the 1990s Tc-99m NOET, another neutral, lipophilic compound, appeared promising in various experimental models as a myocardial perfusion agent. However, despite its favorable myocardial extraction and moderate washout, it showed prominent pulmonary uptake and inconsistent image quality in humans. ${ }^{29,30}$ It has not been submitted for FDA approval. During the same decade Tc-99m tetrofosmin (TF), a lipophilic cationic phosphine complex, was studied as a potential compound for myocardial perfusion imaging. TF, like MIBI, has moderate myocardial extraction with avid retention in myocyte mitochondria and also shows a plateau in myocardial uptake at levels of coronary flow higher than $2 \mathrm{~mL} /$ minute/g. ${ }^{31,32}$ Showing utility for the diagnosis of $\mathrm{CAD},{ }^{33} \mathrm{TF}$ was approved by the FDA in 1996. While a clinical advantage of TF is a somewhat faster hepatic clearance than MIBI, hepatic uptake of TF can still be problematic in some patients.

In this issue of the Journal of Nuclear Cardiology Kim et al evaluate Tc-99m-N-MPO (MPO) as a potential myocardial perfusion agent. This nitrido complex ${ }^{34-37}$ has some similarities in structure to another complex, Tc-99m-N-DBODC5, ${ }^{38-41}$ and is also synthesized with the goal of speeding hepatic clearance while maintaining myocardial image quality. While the discussion above suggests caution in predicting clinical utility from preliminary animal data, the authors have evaluated MPO in different animal species and compare some of their data to those for MIBI. Like MIBI, MPO is a lipophilic cation. Initial cell fractionation data showing similar tracer retention for the two complexes in mitochondria, and serial distribution in rodents showing stable myocardial uptake and low lung uptake, are presented to predict myocardial images similar to MIBI. Serial organ uptake and planar imaging showing rapid hepatic clearance of MPO are presented to predict the feasibility of early myocardial imaging without interference from adjacent organ activity. However, while the images and data show rapid clearance of hepatic activity, prominent splanchnic activity persists. Since the presence of prominent bowel activity adjacent to the heart can sometimes be a challenge for interpretation of clinical myocardial perfusion studies with MIBI or TF, human studies will be important to determine if this is also an issue for MPO.

MIBI and TF achieve good myocardial image quality with excellent myocardial contrast against low background pulmonary tracer uptake. Despite underestimation of hyperemic coronary flow, these tracers accurately detect coronary artery disease. However, prominent early hepatic uptake remains a limitation that delays imaging at rest or after pharmacologic stress, and this can be especially problematic when attenuation correction emphasizes hepatic and splanchnic tracer activity. Despite the clinical success of Tc-99m-based myocardial perfusion imaging, the development of new Tc-99m complexes with favorable kinetics for faster imaging has been slow. It was 13 years between the FDA approval of Tl-201 and approval of the first Tc$99 \mathrm{~m}$-labelled myocardial perfusion agents. It has now been 13 years since the last Tc-99m myocardial perfusion agent was approved. If rapid hepatic clearance of new Tc-99m complexes such as MPO is shown to permit high-quality myocardial images together with a clinically significant reduction in imaging delay, this will be a welcome addition to currently approved perfusion agents.

\section{References}

1. Zaret BL, Strauss HW, Martin ND, Wells HP Jr, Flamm MD Jr. Noninvasive regional myocardial perfusion with radioactive potassium: Study of patients at rest, with exercise and during angina pectoris. N Engl J Med 1973;288:809-12.

2. Lebowitz E, Greene MV, Fairchild R, Bradley-Moore PR, Atkins HL, Ansari AN, et al. Thallium-201 for medical use. I. J Nucl Med 1975;16:151-5. 
3. Nielsen AP, Morris KG, Murdock R, Bruno FP, Cobb FR. Linear relationship between the distribution of thallium-201 and blood flow in ischemic and nonischemic myocardium during exercise. Circulation 1980;61:797-801.

4. Grunwald AM, Watson DD, Holzgrefe HH Jr, Irving JF, Beller GA. Myocardial thallium-201 kinetics in normal and ischemic myocardium. Circulation 1981;64:610-8.

5. Leppo JA, MacNeil PB, Moring AF, Apstein CS. Separate effects of ischemia, hypoxia, and contractility on thallium-201 kinetics in rabbit myocardium. J Nucl Med 1986;27:66-74.

6. Pohost GM, Zir LM, Moore RH, McKusick KA, Guiney TE, Beller GA. Differentiation of transiently ischemic from infarcted myocardium by serial imaging after a single dose of thallium-201. Circulation 1977;55:294-302.

7. Deutsch E, Bushong W, Glavan KA, Elder RD, Sodd VJ, Scholz $\mathrm{KL}$, et al. Heart imaging with cationic complexes of technetium. Science 1981;214:85-6.

8. Kampf G, Muenze R, Knop G, Seifert S. Evaluation of potential heart affine compounds by use of the isolated perfused rat heart. Eur J Nucl Med 1987;13:410-5.

9. Okada RD, Williams SJ, Glover DK, Dragatokis D. Cardiac imaging and myocardial kinetics of technetium-tertiary butylisonitrile during dipyridamole-induced hyperemia. Am Heart J 1988;116:979-88.

10. Gerson MC, Deutsch EA, Nishiyama H, Libson KF, Adolph RJ, Grossman LW, et al. Myocardial perfusion imaging with ${ }^{99 \mathrm{~m}} \mathrm{Tc}$ DMPE in man. Eur J Nucl Med 1983;8:371-4.

11. Gerson MC, Deutsch EA, Libson KF, Adolph RJ, Ketring AR, Vanderheyden J-L, et al. Myocardial scintigraphy with ${ }^{99 \mathrm{~m}} \mathrm{Tc}$-trisDMPE in man. Eur J Nucl Med 1984;9:403-7.

12. Sia IB, Holman BL, McKusick K, Rigo P, Gillis F, Sporn V, et al. The utilization of Tc-99m-TBI as a myocardial perfusion agent in exercise studies: Comparison with Tl-201 thallous chloride and examination of its biodistribution in humans. Eur J Nucl Med 1986;12:333-6.

13. Gerundini P, Savi A, Gilardi MC, Margonato A, Vicedomini G, Zecca L, et al. Evaluation in dogs and humans of three potential technetium-99m myocardial perfusion agents. J Nucl Med 1986;27:409-16

14. Deutsch E, Ketring AR, Libson K, Vanderheyden J-L, Hirth WW. The Noah's ark experiment: Species dependent biodistributions of cationic ${ }^{99 \mathrm{~m}}$ Tc complexes. Nucl Med Biol 1989;16:191-232.

15. Maublant JC, Moins N, Gachon P. Uptake and release of two new Tc-99m labeled myocardial blood flow imaging agents in cultured cardiac cells. Eur J Nucl Med 1989;15:180-2.

16. Maublant JC, Moins N, Gachon P, Renoux M, Zhang Z, Veyre A. Uptake of technetium- $99 \mathrm{~m}$-teboroxime in cultured myocardial cells: Comparison with thallium-201 and technetium-99m-sestamibi. J Nucl Med 1993;34:255-9.

17. Beanlands R, Muzik O, Nguyen N, Petry N, Schwaiger M. The relationship between myocardial retention of technetium- $99 \mathrm{~m}$ teboroxime and myocardial blood flow. J Am Coll Cardiol 1992;20:712-9.

18. Stewart RE, Schwaiger M, Hutchins GD, Chiao P, Gallagher KP, Nguyen N, et al. Myocardial clearance kinetics of technetium99m-SQ30217: A marker of regional myocardial blood flow. J Nucl Med 1990;31:1183-90.

19. Rumsey WL, Rosenspire KC, Nunn AD. Myocardial extraction of teboroxime: Effects of teboroxime interaction with blood. J Nucl Med 1992:33:94-101.

20. Dahlberg ST, Gilmore MP, Leppo JA. Interaction of technetium 99m-labeled teboroxime with red blood cells reduces the compound's extraction and increases apparent cardiac washout. J Nucl Cardiol 1994;1:270-9.
21. Seldin DW, Johnson LL, Blood DK, Muschel MJ, Smith KF, Wall RM, et al. Myocardial perfusion imaging with technetium- $99 \mathrm{~m}$ SQ30217: Comparison with thallium-201 and coronary anatomy. J Nucl Med 1989;30:312-9.

22. Carvalho PA, Chiu ML, Kronauge JF, Kawamure M, Jones AG, Holman BL, et al. Subcellular distribution and analysis of technetium-99m-MIBI in isolated perfused rat hearts. J Nucl Med 1992;33:1516-21.

23. Leppo JA, Meerdink DJ. Comparison of the myocardial uptake of a technetium-labeled isonitrile analogue and thallium. Circ Res 1989;65:632-9.

24. Glover DK, Ruiz M, Edwards NC, Cunningham M, Simanis JP, Smith WH, et al. Comparison between $201 \mathrm{Tl}$ and $99 \mathrm{mTc}$ sestamibi uptake during adenosine-induced vasodilation as a function of coronary stenosis severity. Circulation 1995;91:81320.

25. Miller DD, Donohue TJ, Younis LT, Bach RG, Aguirre FV, Wittry $\mathrm{MD}$, et al. Correlation of pharmacological $99 \mathrm{mTc}$-sestamibi myocardial perfusion imaging with poststenotic coronary flow reserve in patients with angiographically intermediate coronary artery stenoses. Circulation 1994;89:2150-60.

26. Hendel RC, McSherry B, Karimeddini M, Leppo JA. Diagnostic value of a new myocardial perfusion agent, teboroxime (SQ30217), utilizing a rapid planar imaging protocol: Preliminary results. J Am Coll Cardiol 1990;16:855-61.

27. Smith AM, Gullberg GT, Christian PE, Datz FL. Kinetic modeling of teboroxime using dynamic SPECT imaging of a canine model. J Nucl Med 1994;35:484-95.

28. Chua T, Kiat H, Germano G, Takemoto K, Fernandez G, Biasio Y, et al. Rapid back to back adenosine stress/rest technetium-99m teboroxime myocardial perfusion SPECT using a triple-detector camera. J Nucl Med 1993;34:1485-93.

29. Vanzetto G, Fagret D, Ghezzi C. Tc-99m N-NOET: Chronicle of a unique perfusion imaging agent and a missed opportunity? J Nucl Cardiol 2004;11:647-50.

30. Vanzetto G, Calnon DA, Ruiz M, Watson DD, Pasqualini R, Beller GA, et al. Myocardial uptake and redistribution of $99 \mathrm{mTc}$ $\mathrm{N}-\mathrm{NOET}$ in dogs with either sustained coronary low flow or transient coronary occlusion: comparison with $201 \mathrm{Tl}$ and myocardial blood flow. Circulation 1997;96:2325-31.

31. Sinusas AJ, Shi Q-X, Saltzberg MT, Vitols P, Jain D, Wackers FJTh, et al. Technetium-99m-tetrofosmin to assess myocardial blood flow: Experimental validation in an intact canine model of ischemia. J Nucl Med 1994;35:664-71.

32. Glover DK, Ruiz M, Yang JY, Smith WH, Watson DD, Beller GA. Myocardial 99mTc-tetrofosmin uptake during adenosine-induced vasodilatation with either a critical or mild coronary stenosis: Comparison with $201 \mathrm{Tl}$ and regional myocardial blood flow. Circulation 1997;96:2332-8.

33. Zaret BL, Rigo P, Wackers FJ, Hendel RC, Braat SH, Iskandrian AS, et al. Myocardial perfusion imaging with $99 \mathrm{mTc}$ tetrofosmin. Comparison to $201 \mathrm{Tl}$ imaging and coronary angiography in a phase III multicenter trial. Tetrofosmin International Trial Study Group. Circulation 1995;91:313-9.

34. He Z, Hsieh WY, Kim YS, Liu S. Evaluation of novel cationic $99 \mathrm{mTc}(\mathrm{I})$-tricarbonyl complexes as potential radiotracers for myocardial perfusion imaging. Nucl Med Biol 2006;33: 1045-53.

35. Kim YS, Wang J, Broisat A, Glover DK, Liu S. Tc-99m-N-MPO: novel cationic Tc-99m radiotracer for myocardial perfusion imaging. J Nucl Cardiol 2008;15:535-46.

36. Kim YS, He Z, Hsieh WY, Liu S. Impact of bidentate chelators on lipophilicity, stability, and biodistribution characteristics of cationic 99mTc-nitrido complexes. Bioconjug Chem 2007;18:929-36. 
37. Liu S, He Z, Hsieh WY, Kim YS. Evaluation of novel cationic (99m)Tc-nitrido complexes as radiopharmaceuticals for heart imaging: Improving liver clearance with crown ether groups. Nucl Med Biol 2006;33:419-32.

38. Bolzati C, Cavazza-Ceccato M, Agostini S, Tokunaga S, Casara D, Bandoli G. Subcellular distribution and metabolism studies of the potential myocardial imaging agent $[99 \mathrm{mTc}(\mathrm{N})(\mathrm{DBODC})$ (PNP5)]+. J Nucl Med 2008;49:1336-44.

39. Cittanti C, Uccelli L, Pasquali M, Boschi A, Flammia C, Bagatin $\mathrm{E}$, et al. Whole-body biodistribution and radiation dosimetry of the new cardiac tracer 99mTc-N-DBODC. J Nucl Med 2008;49:1299304.
40. Hatada K, Ruiz M, Riou LM, Lima RL, Goode AR, Watson DD, et al. Organ biodistribution and myocardial uptake, washout, and redistribution kinetics of Tc-99m N-DBODC5 when injected during vasodilator stress in canine models of coronary stenoses. $\mathrm{J}$ Nucl Cardiol 2006;13:779-90.

41. Hatada K, Riou LM, Ruiz M, Yamamichi Y, Duatti A, Lima RL, et al. 99mTc-N-DBODC5, a new myocardial perfusion imaging agent with rapid liver clearance: Comparison with $99 \mathrm{mTc}$-sestamibi and 99mTc-tetrofosmin in rats. J Nucl Med 2004;45:2095101. 